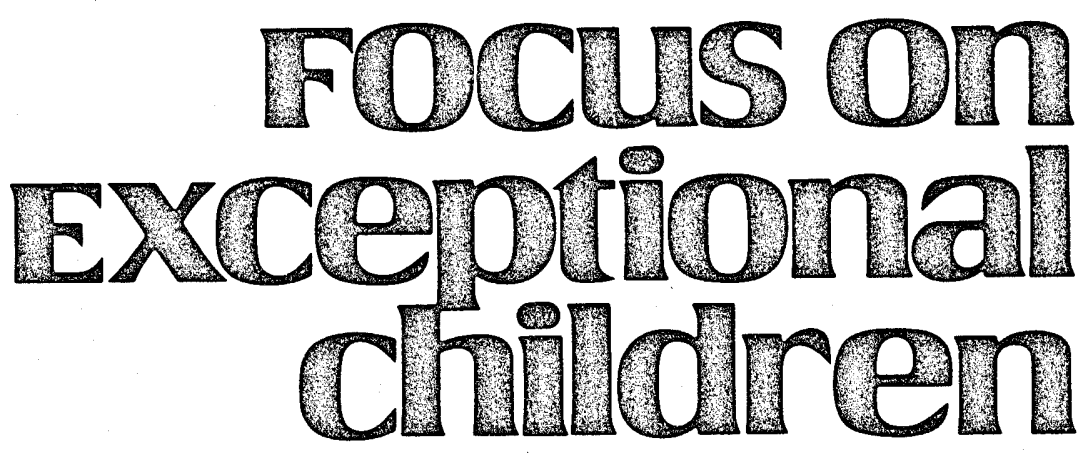

\title{
Prereferral Intervention to Increase Attention and Work Productivity Among Difficult-To-Teach Pupils
}

\author{
Douglas Fuchs, Lynn Fuchs, Michael Bahr, \\ Peggy Reeder, Susan Gilman, Pamela Fernstrom, and Holley Roberts
}

Since the U.S. Department of Education's first child count in 1976-77, the number of students served under the Education for All Handicapped Children Act and Chapter 1 has grown each year, with an increase of 712,688 children, or $16 \%$, from 1976-77 to 1986-87 (see U.S. Department of Education, 1988, p.4). To some extent this growth is a result of legal, legislative, and professional initiatives helping to assure handicapped youth a free and appropriate education. There is increasing suspicion, however, that too many children are being identified as handicapped. Incorrect identification is undesirable for numerous and obvious reasons, including the unnecessary separation and stigmatization of children (e.g., Reynolds \& Balow, 1972), disruption of school programs (e.g., Will, 1986), and high costs (e.g., Singer, 1988).

\section{TEACHER REFERRALS}

Contributing to the apparent overidentification of handicapped children is a large number of teacher referrals. New referrals for the 1984-85 school year, reported by 28 large urban districts (Research for Better Schools, 1986), ranged from a low of 600 (Memphis) to a high of 33,855 (New York City). The median number of new referrals for the districts was 2,358 . Over half of these students were certified handicapped, indicating the importance of teacher referral to eventual special education placement.

Many students referred for testing and possible special education placement are characterized as "off-task," or by related adjectives such as "inattentive," "distractible," and "unproductive" (Bahr, Fuchs, Stecker, Goodman, \& Fuchs, 1988; Hutton, 1985). Offtask behavior also seems to describe many children eventually labeled learning disabled (LD) as indicated by teacher ratings (e.g., Eliason \& Richman, 1988; Epstein, Cullinan, \& Lloyd, 1986; Epstein, Cullinan, \& Rosemier, 1983; Quay \& Peterson, 1987) and observations of LD pupils' classroom behavior (e.g., Bender, 1985; Bryan, 1974; Feagans \& McKinney, 1981; Fellers \& Saudargas, 1987; McKinney, McClure, \& Feagans, 1982; Richey \& McKinney, 1978). Not surprisingly, LD students' inattention seems negatively related to academic success (e.g., McKinney \& Feagans, 1984; McKinney \& Speece, 1983).

The authors are all affiliated with the Department of Special Education, George Peabody College of Vanderbilt University. 
Given the apparent importance of off-task behavior in describing both difficult-to-teach (DTT) nonhandicapped students and many pupils identified as learning disabled, we developed a classroom-based intervention designed to increase DTT students' on-task behavior and academic productivity, hoping that such improvement would reduce the likelihood of referral. Development of this prereferral intervention is part of a 3-year research project known as "Mainstream Assistance Teams," funded by the Office of Special Education, U.S. Department of Education. To provide a meaningful description of the intervention, we first must describe several other dimensions of this project.

\section{MAINSTREAM ASSISTANCE TEAMS}

The purpose of Mainstream Assistance Teams (MAT) has been to work with a large urban school district to implement prereferral interventions in elementary and middle schools. Some of these interventions focus on improving social behavior; others address the related problems of

\section{FOCus on Exceptional children}

ISSN 0015-511X FOCUS ON EXCEPTIONAL CHILDREN (USPS 203-360) is published monthly except June, July, and August as a service to teachers, special educators, curriculum specialists, administrators, and those concerned with the special education of exceptional children. This publication is annotated and indexed by the ERIC Clearinghouse on Handicapped and Gifted Children for publication in the monthly Current Index to Journals in Education (CIJE) and the quarterly index, Exceptional Children Education Resources (ECER). It is also available in microfilm from University Microfilms International, Ann Arbor, MI 48106. Subscription rates: Individual, \$27 per year; institutions, $\$ 36$ per year. Copyright (c) 1990, Love Publishing Company. All rights reserved. Reproduction in whole or part without written permission is prohibited. Printed in the United States of America. Second class postage is paid at Denver, Colorado. POSTMASTER: Send address changes to:

$$
\begin{aligned}
& \text { Love Publishing Company } \\
& \text { Executive and Editorial Office } \\
& 1777 \text { South Bellaire Street } \\
& \text { Denver, Colorado } 80222 \\
& \text { Telephone (303) 757-2579 }
\end{aligned}
$$

Edward L. Meyen

University of Kansas
Glenn A. Vergason Georgia State University
Richard J. Whelan

University of Kansas Medical Center

Stanley F. Love

Carolyn Acheson inattention and low academic productivity. All are embedded within a larger process of teacher consultation known as behavioral consultation.

\section{Behavioral Consultation}

Behavioral consultation requires a consultant to intervene directly with a DTT student through discussion with the student's teacher. Consultation is conducted during a series of four interrelated stages: problem identification, problem analysis, plan implementation, and problem evaluation. The consultant guides the teacher through these stages in a succession of structured meetings in which specific objectives must be accomplished before consultation can proceed to subsequent stages.

In problem analysis, the second stage in the model's sequence, the consultant and teacher engage in collaborative problem solving. This entails development of classroom-based interventions, mutually determined by the teacher and the consultant. In the first year of the MAT project, consultants were trained to use collaborative problem solving. The results were mixed. Whereas some interventions were planned and implemented carefully, many others were of weak design or conducted inconsistently (Fuchs \& Fuchs, in press).

\section{MAT Interventions}

\section{Prescriptive}

During the next 2 years we attempted to strengthen the design and implementation of the interventions by requiring use of teacher-student contracts and specific monitoring procedures. So, following Year 1 of the project, Peabody staff, rather than consultant-teacher teams, selected several research-supported interventions and developed instructions and materials to guide their use. In so doing, we sacrificed some consultant-teacher collaboration to help ensure accurate implementation of judiciously selected interventions.

\section{Student-Directed}

These relatively prescriptive MAT interventions require DTT students to play an active, central role. After the first 2 days, when the classroom teacher implements all activity, students take over. They systematically monitor, chart, and evaluate their own behavior and provide verbal feedback to themselves. This self-regulatory activity was adopted for two reasons. First, evidence suggests that it helps reduce 
inappropriate classroom behavior (e.g., Hallahan, Lloyd, Kosiewicz, Kauffman, \& Graves, 1979), and at the same time it seems to increase academic productivity (e.g., Hallahan \& Sapona, 1983). Second, because the student is responsible for conducting much of the intervention, teachers tend to view it as unobtrusive-_"do-able" (e.g., Rhode, Morgan, \& Young, 1983; Rosenbaum \& Drabman, 1979).

\section{Designed to Transfer to Additional School Settings}

MAT interventions were developed not only to induce behavior change in an initial classroom, but also to facilitate its transfer to other classrooms. With this goal in mind, we borrowed an idea from Stokes and Baer (1977), called "sequential modification," and constructed interventions to be conducted in four phases. The first phase is relatively complex, but successive phases become more and more simple. The purpose of sequential modification is to reduce teacher and student intervention-related responsibilities so that the strategies become more feasible and can be applied easily in additional settings.

\section{PREREFERRAL INTERVENTION}

The following discussion is of a prereferral intervention designed to increase attentiveness and work productivity, as well as the behavioral consultation process in which it is embedded. The intervention is organized according to three basic phases: pre-intervention, intervention, and post-intervention activity.

\section{Pre-Intervention Activity}

\section{Meeting \#1: Identifying and Defining the Problem}

Using a written script (see Fuchs, Fuchs, Reeder, Gilman, Bahr, Fernstrom, \& Moore, 1989), the schoolbased consultant asks the teacher to describe a most DTT student. The consultant next encourages the teacher to specify as many as six behaviors that make this student difficult to teach. The teacher rates each problem from 1 to 5 in terms of severity, manageability, and tolerability, and then selects the one behavior that, if remedied, would do most to improve the "teachableness" of the student. Finally, the teacher and consultant formulate a concrete, observable description of this most salient behavior problem.

As indicated, a frequently mentioned problem is "off task," which might be defined as "fiddling with things like a pencil or notebook during math class." The definition is used (a) by the consultant to observe the DTT student before and after the intervention is implemented and (b) by the teacher to help the student understand the problem behavior.

\section{Observing Classroom Behavior}

Interval Recording. Following Meeting \#1, the consultant conducts 20 -minute observations in the classroom on two days, to validate the seriousness of the problem behavior and to establish a baseline of its frequency. The consultant uses an "interval recording" system. Each 1-minute interval is divided into six 10-second segments. Each 10-second interval is divided into 8 seconds for observing and 2 seconds for recording.

Observing the DTT Student and Peers. After observing for 8 seconds, the consultant records a plus sign ( + ) if the problem behavior was observed or a minus sign (-) if it was not observed. Thus, the consultant records six marks for each 1-minute interval. In addition to the DTT student, two randomly selected same-sex classmates are observed. The consultant observes the DTT student in the first minute, peer \#1 in the second minute, back to the DTT student during the third minute, and peer \#2 in the fourth minute. This rotation is continued for 20 minutes on each of the 2 days.

Computing Percentages. After the second day of observation, the consultant computes the DTT student's percentage of problem behavior by taking the total number of plus signs for the two days and dividing it by the total number of plus and minus signs. This yields an initial or pre-intervention percentage of problem behavior. An identical procedure is followed for computing a combined pre-intervention percentage of the two peers' behavior.

\section{Collecting Work Samples}

Before Meeting \#2 the teacher collects five samples of the student's work produced during the class in which the intervention will be implemented. The teacher evaluates these samples in terms of amount and accuracy of work completed before giving them to the consultant in Meeting \#2.

\section{Meeting \#2: Setting Goals and Planning the Intervention}

Long-Term Goal for the Problem Behavior. In Meeting \#2 the consultant reports the observation data to the classroom teacher. If the observations do not corroborate the teacher's estimation of the frequency, or seriousness, of the problem behavior, a new description is formulated and the consul- 
tant conducts two additional observations. If, however, the observations support the teacher's estimate, the teacher and consultant use the data to set a long-term goal for behavior change - a goal signifying the magnitude of change expected by the end of the intervention. This goal is expressed in absolute terms (e.g., as a reduced percentage of DTT student's "fiddling") and in relative terms (e.g., as a smaller difference between the percentages of the DTT student's and peers" "fiddling").

Short-Term Goals and a Contract for Academic Performance. The consultant also explains that the intervention will include a teacher-student contract, specifying daily goals for classroom performance on work assignments. Using the student's pre-intervention work samples as a guide, the consultant and teacher decide on reasonable goals (a) for an amount of work to be completed (e.g., at least 20 of 30 items completed on a math worksheet) and (b) a percentage of work to be completed correctly (e.g., a minimum of 15 of 20 items, or $75 \%$, calculated correctly).

Long- and short-term goals are established for a specific class such as math. Whereas the long-term behavior goal remains constant throughout the intervention, the shortterm academic goals may change frequently. It is assumed that repeated achievement of the daily academic goals will translate eventually into successful attainment of the student's behavior goal. As the pupil meets daily goals for amount and accuracy of work completed, his or her frequency of "fiddling" is expected to decrease.

In addition to a teacher-student contract, the prereferral intervention involves special monitoring procedures and the possibility of rewards to encourage positive behavior change. These rewards can be of various sorts such as activities (e.g., free time), objects (e.g., stickers), or tokens to trade for back-up reinforcers. To enhance the importance of the rewards to the students, teachers are encouraged to permit the students to choose the rewards.

\section{Teacher-Student Talk}

After Meeting \#2 the teacher meets with the student to identify and describe the problem behavior. The teacher explains, for example, how frequent "fiddling" with things interferes with the student's math performance. The teacher then describes a corresponding desirable behavior- for example, "completing math assignments without fiddling." The teacher conveys confidence in the student's capacity to demonstrate this more adaptive behavior and expresses the expectation that he or she will display it more often.
After agreeing on the nature of the problem and the more desirable behavior, the teacher and student develop a written contract. It specifies: (a) the daily goals for amount and accuracy of work completion, established by the teacher and consultant during Meeting \#2, (b) a particular class time and activity during which work will be monitored, (c) a reward the student will receive if the daily goals are met, and (d) dates on which the contract starts and ends. Finally, the teacher and student sign the contract.

\section{Intervention Activity}

\section{Phase 1}

Daily goals. Prior to the academic activity specified by the contract, the teacher stipulates the number of items to be completed, the number of items to be completed correctly, and the number of minutes the student may devote to the assignment. The teacher writes this time limit and the amount and accuracy goals in Part A of the monitoring sheet (see Figure 1). Using a green crayon, the student draws a line corresponding to the amount goal in the "Items COMPLETED" graph; with a red crayon, he or she indicates the accuracy goal by drawing a line on the "Items CORRECT" graph (see Part B of Figure 1).

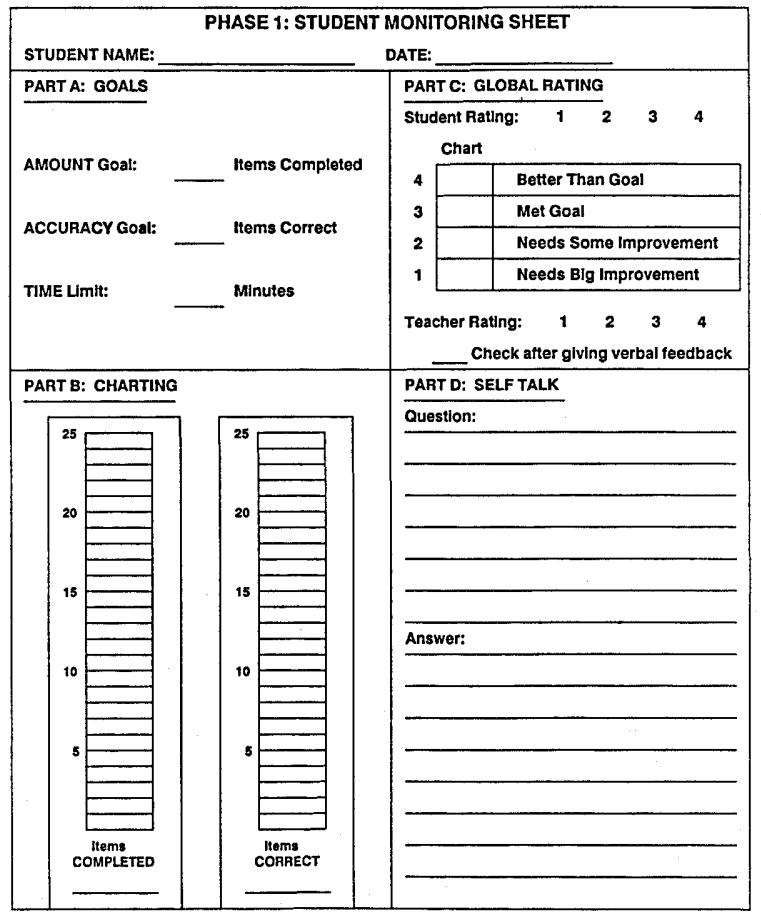

FIGURE 1

Phase I Monitoring Sheet 
Charting. The teacher makes certain the student understands the assignment, and instructs the student to start work. When time expires, the student stops work and determines his or her accuracy of performance with a scoring key supplied by the teacher. The student records the number of items completed and number of items correct on lines under the appropriate graphs in Part B. Then, using green and red crayons for the "Items COMPLETED" and "Items CORRECT" graphs, respectively, the student colors the graphs to indicate the amount and accuracy of his or her performance for the day.

Global Ratings. Charting performance in the manner just described helps the student determine whether the daily goals were met. Using a green crayon, the student circles a global rating of: 4 (better than goal), 3 (met goal), 2 (needs some improvement), or 1 (needs big improvement), and colors the appropriate number of levels on the chart in Part $\mathrm{C}$ of the monitoring sheet (see Figure 1). The teacher reviews this rating with the student. If there is a difference of opinion as to whether the daily goals were met, the teacher pursues a compromise by reviewing with the student the nature of the amount and accuracy goals and by checking the accuracy with which the student corrected his or her work. Once agreement on a rating is reached, the teacher circles it at the bottom of Part $\mathrm{C}$ of the monitoring sheet (see Figure 1).

Self-Talk Question and Answer. The student also is responsible for writing a self-talk question and answer in Part D of the monitoring sheet. These are formulated with teacher help and reflect the nature of the desired behavior, defined for the student during the teacher-student talk prior to Phase 1.

Using our example, the student's self-talk question might be, "Did I complete my math assignment today without fiddling with things on my desk?" If the student and teacher have agreed on a global rating of 3 , the student might answer, "Yes, I completed my work without fiddling." If, however, the agreed-upon global rating is 2 , the student might answer, "No, I played with things on my desk and did not finish my work. I will do better tomorrow."

Reinforcement. The teacher is encouraged to dispense two types of reinforcement. The first is verbal, and its message is tied directly to the global rating. Following are examples of appropriate verbal reinforcement:

Rating of 4: "Great! You did excellent work today!" Rating of 3: "I'm happy to see you completed your work."

\section{Rating of 2: "You're on the right track. Work harder tomorrow." \\ Rating of 1: "Keep working and do better tomor- row."}

If teacher and student agree that goals were met, the student also receives the reward described in the teacher-student contract.

Fidelity of Implementation. As indicated, the teacher implements Phase 1 for the first two days before the student assumes the job of monitoring. Thus, the teacher becomes familiar with the process and capable of teaching it to the student. A consultant observes the teacher on one of these first two days. Later, the consultant observes the student during one of the student's first two days of implementing the intervention. The consultant conducts these observations to verify that the intervention is being implemented correctly. The student uses the Phase 1 monitoring sheets for five days or until the daily goals are achieved three times, whichever comes first, before moving to Phase 2.

\section{Phase 2, Phase 3, and Observations}

Phase 2. In Phase 2 the student no longer charts the daily amount and accuracy goals. Thus, Part B of the monitoring sheet (see Figure 1) is eliminated from Phase 2 procedures. But the teacher still writes a time limit and daily goals in Part A of the monitoring sheet, and the teacher and student continue to assign global ratings to the student's performance. Additionally, the student continues to chart a global rating and to employ a self-talk question and answer; the teacher still provides verbal reinforcement in accordance with the rating, and rewards the student when appropriate. The student uses Phase 2 monitoring sheets for five days, or until the goal is met on three days, whichever comes first.

Phase 3. Phase 3 procedures are fewer still. The student no longer charts a global rating. Rather, he or she simply notes the teacher's time limit and daily goals, completes the work assignment, checks it for correctness, and designates, in Part $\mathrm{C}$ of the monitoring sheet (see Figure 2), a global rating for his or her performance. The teacher continues to assign a final global rating; the student writes the self-talk question and answer (see Part D of Figure 2); and the teacher provides verbal feedback and rewards when appropriate. As in prior phases, the student remains in Phase 3 for five days, or until the goal is met on three days, whichever comes first. 


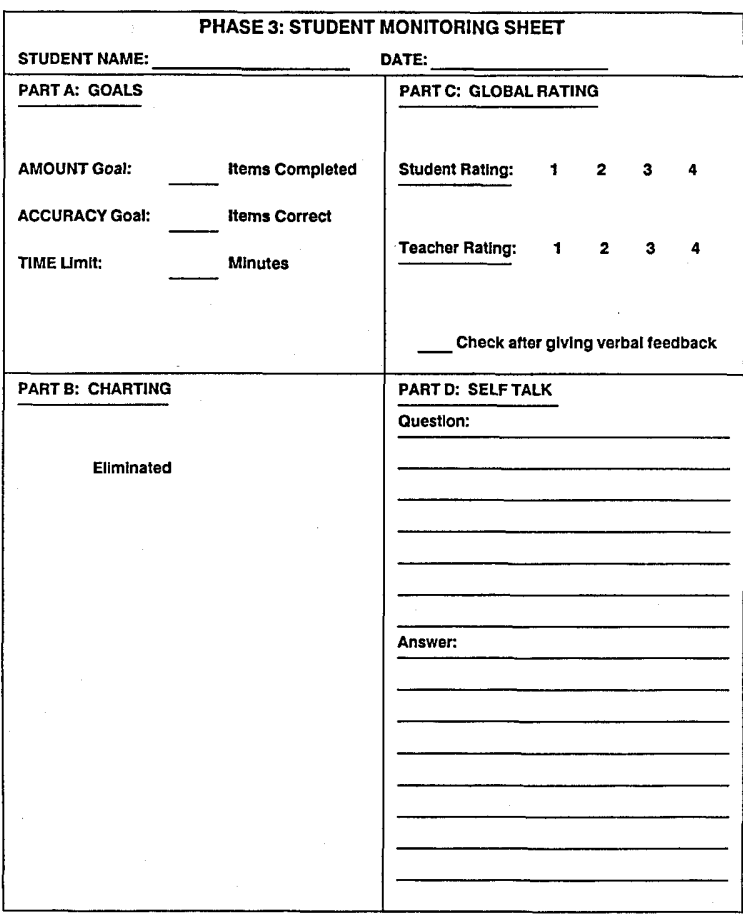

FIGURE 2

Phase 3 Monitoring Sheet

Observations. At the end of Phase 3, the consultant conducts post-intervention observations of the same behavior (e.g., "off task") that was observed prior to implementation of the intervention. The consultant is careful to use the same definition and procedures as employed during the preintervention observations. In Meeting \#3, described later, these data are compared with pre-intervention observations to determine whether the intervention was effective.

\section{Phase 4}

Transfer classroom. The purposes of the fourth and final phase are (a) to continue the simplified Phase 3 version of the intervention in the first classroom and, concurrently, (b) to implement the same simplified version in a second, "transfer" classroom. The teacher and consultant select a transfer setting after considering three factors: First, the student must exhibit similar problem behavior in this transfer classroom; second, the transfer setting must represent an academic area (e.g., science); and third, the teacher of the transfer classroom must be willing to participate.

The teacher of the first classroom describes to the transfer teacher the student's problem behavior and correspond- ing desirable behavior. The first teacher also explains: use of amount and accuracy goals with daily assignments; the relation between the student's performance and the four global ratings; the connection between the global ratings and verbal feedback and rewards.

Goal Setting. The first teacher then talks with the DTT student about the transfer classroom. He or she identifies the transfer teacher and explains how the student will now monitor performance on work assignments in two classrooms. The student is told the daily goals and that they will remain the same in the two classrooms for the duration of Phase 4. Most important, the first teacher makes clear that the student will continue to receive a reward only if the student and both teachers agree that goals were met or exceeded in their respective classrooms.

Global Ratings. For each day of Phase 4, the student completes two Phase 3 monitoring sheets, one for the first classroom and one for the transfer classroom. On each sheet the student makes note of the time limit and the daily amount and accuracy goals stipulated by the teachers and, following completion of the work period, the student assigns a global rating. Before leaving the transfer class, the student and transfer teacher review the student's global rating and discuss any disagreements about whether the student met the goals. Once agreement is reached, the transfer teacher records a global rating on the monitoring sheet for the transfer class. Similarly, the first teacher reviews the student's global rating for performance in his or her classroom and assigns a rating on the monitoring sheet.

Reinforcement and Reward. After the school day the student and initial teacher meet to review the two monitoring sheets. Verbal feedback reflects both teacher ratings. For example, if the first teacher assigned a rating of 3 and the transfer teacher (Mr. Smith) a rating of 2, the first teacher might say to the student, "You need to work harder in Mr. Smith's class, but you did very well in my class." In addition, if the daily goals were met in both the first and transfer classrooms, the student would receive a reward for the day. The student remains in Phase 4 for a minimum of two days.

Observations in the Transfer Classroom. To determine whether the MAT intervention transferred to additional school settings, the project staff conducted several sets of observations in transfer classrooms. (For more information about these observations, see Fuchs, 1989.) 


\section{Post-Intervention Activity}

\section{Meeting \#3}

The primary purpose of Meeting \#3 is for the first teacher and the consultant to determine whether the goal set in Meeting \#2 has been achieved. Regarding data collected only in the initial classroom, the teacher and the consultant compare the percentage of problem behavior demonstrated by the DTT student and peers during pre-intervention observations to the percentage displayed during post-intervention observations (Phase 3 ). The difference is contrasted with the goal set in Meeting \#2. If the goal has been met, or if it has not been achieved but consultant and teacher decide that sufficient progress has been made, they agree to end consultation and plan a slow fade of intervention procedures. The teacher, guided by the consultant, then reviews the six specific behavior problems identified in Meeting \#1 and, as before, gives each of them a ranking from 1 to 5 with regard to severity, manageability, and tolerability.

If the teacher believes that progress has been insufficient, the teacher and the consultant choose among four options: To continue consultation (1) with the same goal and same unmodified classroom intervention; (2) with a different goal and same unmodified intervention; (3) with the same goal and a modified intervention; or (4) with a different goal and a different intervention. During this meeting the consultant and teacher work out what the goal and intervention procedures will be for continued consultation, including another classroom visit by the consultant to determine fidelity of intervention implementation, another observation of the DTT student and peers, and a fourth and final meeting (see Fuchs, Fuchs, Reeder et al., 1989, for details).

\section{DOES THE MAT INTERVENTION WORK?}

During Years 2 and 3, pre-intervention, post-intervention, and follow-up observation data were collected on 103 DTT pupils (79 experimentals and 24 controls) and 206 randomly selected same-sex peers. These data indicated the intervention dramatically reduced the frequency of most experimental students' problem behaviors. In Year 2, for example, experimental pupils displayed targeted behavior $47 \%, 18 \%$, and $20 \%$ of the time they were observed at "pre," "post," and "follow-up" (3 weeks after "post"), respectively. Corresponding percentages for controls were $41 \%, 38 \%$, and $47 \%$. Moreover, experimental students' frequency of problem behavior was indistinguishable from peers at follow-up (20\% vs. $17 \%)$, whereas control pupils' problem behavior was 9 times more frequent ( $47 \%$ vs. $5 \%$ ).

Pre-intervention grades in observed classrooms for experimental and control students averaged D- and F, respectively. Although at post-intervention this average grade had climbed to $\mathrm{C}$ - for experimentals, it remained $\mathrm{F}$ for controls. Additionally, rating scales and questionnaires administered to teachers of experimental pupils indicated that a majority became more positive toward their DTT pupils. Finally, in Year 3, experimental students were dramatically and significantly less likely to be referred for testing and possible special education placement than were control students. That is, among 48 experimental pupils, only 5 were referred; among controls, 6 of 12 were referred. (For more detailed analysis and discussion of Year 2 and Year 3 data, see Fuchs, in press; Fuchs \& Fuchs, 1988; Fuchs, Fuchs, \& Bahr, 1989).

Nevertheless, an important caveat must be expressed. MAT teachers and consultants had the benefit of technical assistance and support from Peabody staff who were in project schools once or twice each week. Thus, we do not know whether the process works without such assistance. An important implication is that practitioners planning to implement this prereferral procedure should obtain pre-and post-intervention data to validate it for their settings. Another reason to collect evaluative data is that the MAT intervention was not, and never will be, universally effective; there will always be children for whom it is unsuccessful. Responsible mainstreaming requires teachers and building-based support staff to document the effects of prereferral intervention on each and every student participant.

\section{REFERENCES}

Bahr, M., Fuchs, D., Stecker, P., Goodman, B., \& Fuchs, L. (1988). Characteristics of students targeted for prereferral intervention. Paper presented at the annual meeting of the National Association of School Psychologists, Chicago.

Bender, W.N. (1985). Differences between learning disabled and nonlearning disabled children in temperament and behavior. Learning Disability Quarterly, 8, 11-18.

Bryan, T.S. (1974). An observational analysis of classroom behavior of children with learning disabilities. Journal of Learning Disabilities, 7, 26-34.

Eliason, M.J., \& Richman, L.C. (1988). Behavior and attention in LD children. Learning Disability Quarterly, 11, 360-369.

Epstein, M.H., Cullinan, D., \& Lloyd, J.W. (1986). Behavior-problem patterns among the learning disabled: III-Replication across age and sex. Learning Disability Quarterly, 9, 43-54.

Epstein, M.H., Cullinan, D., \& Rosemier, R. (1983). Patterns of behavior problems among the learning disabled: Boys aged 6-11. Learning Disability Quarterly, 6, 305-312.

Feagans, L., \& McKinney, J. (1981). The pattern of exceptionality across domains in learning disabled children. Journal of Applied Developmental Psychology, 1, 313-328.

Fellers, G., \& Saudargas, R.A. (1987). Classroom behaviors of LD and nonhandicapped girls. Learning Disability Quarterly, 10, 231-236.

Fuchs, D. (1989). An experimental approach to economizing innovation: Mainstream Assistance Teams. Invited address, Division of Research, presented at the annual meeting of the Council of Exceptional Children, San Francisco. 
Fuchs, D. (in press). Mainstream Assistance Teams: A prereferral intervention system for difficult-to-teach students. In G. Stoner, M. Shinn, \& H. Walker (Eds.), Interventions for achievement and behavior problems. Washington, DC: National Association of School Psychologists.

Fuchs, D., \& Fuchs, L.S. (1988). Mainstream Assistance Teams to accommodate difficult-to-teach students in general education. In J.L. Graden, J.E. Zins, \& M.J. Curtis (Eds.), Alternative educational delivery systems: Enhancing instructional options for all students (pp. 49-70). Washington, DC: National Association of School Psychologists.

Fuchs, D., \& Fuchs, L.S. (in press). Exploring effective and efficient prereferral interventions: A component analysis of behavioral consultation. School Psychology Review.

Fuchs, D., Fuchs, L.S., \& Bahr, M.W. (1989). Mainstream Assistance Teams: A systematic search for an effective and efficient prereferral intervention. In B. Keogh (Chair), Enhancing instruction for difficult-to-teach students: Three years of sponsored research in the mainstream. Symposium presented at the annual meeting of the American Educational Research Association, San Francisco.

Fuchs, D., Fuchs, L., Reeder, P., Gilman, S., Bahr, M., Fernstrom, P., \& Moore, P. (1989). A handbook on prereferral intervention: Mainstream Assistance Teams. Nashville: George Peabody College of Vanderbilt University.

Hallahan, D.P., Lloyd, J., Kosiewicz, M.M., Kauffman, J.M., \& Graves, A.W. (1979). Self-monitoring of attention as a treatment for a learning disabled boy's off-task behavior. Learning Disability Quarterly, 4,413 .

Hallahan, D.P., \& Sapona, R. (1983). Self-monitoring of attention with learning-disabled children: Past research and current issues. Journal of Learning Disabilities, 16, 616-620.

Hutton, J.B. (1985). What reasons are given by teachers who refer problem behavior students? Psychology in the Schools, 22, 79-82.

McKinney, J.D., \& Feagans, L. (1984). Academic and behavioral characteristics of learning disabled children and average achievers: Longitudinal studies. Learning Disability Quarterly, 7, 251-264.

McKinney, J.D., McClure, S., \& Feagans, L. (1982). Classroom behavior patterns of learning disabled children. Learning Disability Quarter$l y, 5,45-52$.

McKinney, J.D., \& Speece, D.L. (1983). Classroom behavior and the academic progress of learning disabled students. Journal of Applied Developmental Psychology, 4, 149-161.
Quay, H.C., \& Peterson, D. (1987). Manual for the Revised Behavior Problem Checklist. Coral Gables, FL: Author.

Research for Better Schools (1986). Special education: Views from America's cities. Philadelphia: Author.

Reynolds, M.C., \& Balow, B. (1972). Categories and variables in special education. Exceptional Children, 38, 357-366.

Rhode, G., Morgan, D.P., \& Young, K.R. (1983). Generalization and maintenance of treatment gains of behaviorally handicapped students from resource rooms to regular classrooms using self-evaluation procedures. Journal of Applied Behavior Analysis, 16, 171-188.

Richey, D., \& McKinney, J. (1978). Classroom behavior patterns in learning disabled children. Journal of Learning Disabilities, 11, 38-43.

Rosenbaum, M.S., \& Drabman, R.S. (1979). Self-control training in the classroom: Review and critique. Journal of Applied Behavior Analysis, 10, 349-367.

Singer, J.D. (1988). Should special education embrace the regular education initiative? Lessons to be learned from the implementation of PL 94-142. Educational Policy, 2, 409-424.

Stokes, T.F., \& Baer, D.M. (1977). An implicit technology of generalization. Journal of Applied Behavior Analysis, 10, 349-367.

U.S. Department of Education, Special Education Programs (1988). Tenth annual report to Congress on the implementation of The Education of the Handicapped Act. Washington: Author.

Will, M. (1986). Educating children with learning problems: A shared responsibility. Exceptional Children, 52, 411-415.

This article was supported by Grant No. G008530158 from the Office of Special Education, U.S. Department of Education, to Vanderbilt University. The article does not necessarily reflect the position or policy of the U.S. Department of Education, and no official endorsement should be inferred.

The authors express appreciation to Nashville-Davidson County Metro Public Schools, without whose cooperation and support this research could not have been conducted. Special thanks are extended to Denise Davis, Andrea Edwards, Jerita Farley, Pat Jernigan, Kay Matthews, Thelma Norris, Mimi Pollack, and Judy Smith, who served as teacher consultants from 1986 through 1988; to their Coordinator, Pat Cole; and to Jim Zerface, Director of Pupil Personnel.

\section{Professional update}

\section{Council for Exceptional Children}

April 23-27, 1990

Toronto, Ontario, Canada

Contact: CEC

1920 Association Drive

Reston, Virginia 22091

\section{American Association on Mental Retardation}

May 27-31, 1990

Atlanta, Georgia

Contact: AAMD(202) 387-1968 